\title{
Рaper
}

\section{Sedative and cardiopulmonary effects of dexmedetomidine infusions randomly receiving, or not, butorphanol in standing horses}

\author{
Luíza Quintão Medeiros, Miguel Gozalo-Marcilla, Polly M Taylor, Daniela Campagnol, \\ Flávia Augusta de Oliveira, Marcos Jun Watanabe, Antonio José de Araujo Aguiar
}

\begin{abstract}
Dexmedetomidine (DEX) alone, or combined with butorphanol (BUT), may be administered by constant rate infusions (CRIs) in standing horses. This blinded, randomised, crossover study in six healthy adult horses aimed to determine the sedative and cardiopulmonary effects of DEX (dexmedetomidine $(3.5 \mu \mathrm{g} / \mathrm{kg}+5 \mu \mathrm{g} / \mathrm{kg} / \mathrm{hour}$ CRI) and DEX/BUT (dexmedetomidine (3.5 $\mu \mathrm{g} / \mathrm{kg}+3.5 \mu \mathrm{g} / \mathrm{kg} / \mathrm{hour}$ CRI) and butorphanol ( $20 \mu \mathrm{g} / \mathrm{kg}+24 \mu \mathrm{g} / \mathrm{kg} / \mathrm{hour}$ CRI)). Head height above ground (HHAG), ataxia, responses to tactile/auditory stimuli and cardiopulmonary variables were recorded before, at 5/15/30/60/90 minutes and after CRIs terminated (15/30/60 minutes). Repeated measures analysis of variance with Tukey-Kramer test were used for cardiopulmonary values (mean \pm SD) and HHAG reduction (per cent), and Friedman's and Dunn's for non-parametric data $(P<0.05)$. Maximum HHAG reductions of 54 per cent (DEX) and 58 per cent (DEX/BUT) occurred at 15 minutes, with ataxia for 15 minutes in both treatments. Responses to stimuli were reduced for $\mathbf{3 0}$ minutes in both treatments, and auditory up to 60 minutes in DEX. Cardiopulmonary effects typical of $\alpha_{2}$-agonists were observed, with no differences between treatments. At the doses and rates reported here, both regimens provided clinically sufficient sedation for only $\mathbf{3 0}$ minutes.
\end{abstract}

\section{Introduction}

In equine practice, standing protocols are preferred over general anaesthesia as they reduce morbidity, mortality and cost. Combinations of sedatives and analgesics may provide adequate conditions for surgery. In order to maintain sedation and analgesia, drugs should be given as intravenous constant rate infusions (CRIs) to produce steady-state plasma concentrations. This avoids the peaks associated with supplemental injections which may lead to severe cardiopulmonary depression and excessive ataxia.

Xylazine ${ }^{1-3}$ detomidine ${ }^{4-6}$ romifidine $e^{237}$ and medetomidine ${ }^{8-10}$ have been administered by CRI to provide sedation and analgesia in standing horses. Dexmedetomidine (DEX) has a beneficial pharmacological profile with short half-life and rapid redistribution, which favours its use for infusion in horses, ${ }^{11-13}$ for instance, allowing rapid changes in depth of sedation and a rapid recovery

Veterinary Record (2017)

Luíza Quintão Medeiros, DVM, MSc, Daniela Campagnol, DVM, MSc, PhD, Flávia Augusta de Oliveira, DVM, $\mathrm{MSc}, \mathrm{PhD}$,

Graduate Program in Anaesthesiology, Medical School of Botucatu, UNESPUniv Estadual Paulista, Botucatu-SP, Brazil

Miguel Gozalo-Marcilla, DVM, PhD, Dip. ECVAA

Marcos Jun Watanabe, DVM, MSC, $\mathrm{PhD}$

Antonio José de Araujo Aguiar, DVM, MSc, PhD,

Department of Veterinary Surgery and

doi: $10.1136 /$ vr.104359

Anaestesiology, Faculty of Veterinary Medicine and Animal Science, UNESP - Univ Estadual Paulista, Botucatu-SP, Brazil

Polly M Taylor, DVM, PhD, Dp. ECVAA, Taylor Monroe, Ely, UK

E-mail for correspondence: ajaguiar@fmvz.unesp.br

Provenance and peer review Not commissioned; externally peer reviewed.

Received February 12, 2017

Revised June 22, 2017

Accepted July 24, 2017 after the infusion is stopped. After a bolus of $3.5 \mu \mathrm{g} / \mathrm{kg}$, infusion rates of 1 and $1.75 \mu \mathrm{g} / \mathrm{kg} /$ hour have been used in partial intravenous anaesthesia (PIVA) regimens, ${ }^{14-16}$. Recent studies indicate that DEX infusions of 4 and $6 \mu \mathrm{g} / \mathrm{kg} /$ hour were associated with antinociception in standing horses, although plasma concentrations of DEX varied greatly among individuals. ${ }^{12} 17$

Butorphanol (BUT) has been widely used with $\alpha_{2}$-agonists in horses to enhance sedation and analgesia. ${ }^{18-21}$ A BUT CRI provided analgesia and minimised the ataxia and gastrointestinal side effects, such as decreased borborygmi and defecation, which occurred after a single injection. ${ }^{22}$ Infusions of BUT with different $\alpha_{2}$-agonists maintained sufficient sedation in standing horses for surgical procedures to be performed. ${ }^{2324}$ Nevertheless, under experimental conditions, BUT did not decrease the dose of xylazine or romifidine required to maintain sedation in unstimulated healthy horses. ${ }^{17}$

Administration of a DEX CRI in association with BUT has not been reported in standing horses. The study aimed to evaluate the sedative and cardiopulmonary effects of a DET CRI, with or without a BUT infusion. We hypothesised that a reduced rate of DEX infusion when co-administered with a BUT CRI would maintain the same degree of sedation while reducing the side effects related to DEX

\section{Materials and methods}

This blinded study was approved by the FMVZ-UNESP Ethical and Animal Care Committee (protocol \# 128/2008-CEEA).

\section{Animals}

Six healthy, adult experimental horses (four mares and two geldings), of various breeds, aged $14 \pm 4$ years, weighing $432 \pm 25 \mathrm{~kg}$ were studied. They were kept in collective paddocks, fed daily with hay, commercial diet (Extreme Mix - Agroceres Nutrição Animal, Patos de Minas, MG, Brazil) and water ad libitum. The 
sample size was derived from the pilot study to give 80 per cent power to detect a 20 per cent difference in head height above the ground (HHAG) and degree of ataxia with a significance level of 5 per cent.

\section{Instrumentation}

The day before administration of the treatments, the jugular and temporal areas were clipped for placement of venous and arterial catheters, respectively, and for ECG electrodes. Food was withheld for 12 hours before the experiment, but water was provided ad libitum.

On the day of the experiment, the horses were restrained in the stocks located in the research room of our institution, and the skin over the catheter sites was prepared surgically and infiltrated with local anaesthetic (Xylazine, Xylestesin 2\%, Cristália, Itapira, SP, Brazil). A 14 gauge catheter (Angiocath Insyte, Becton Dickinson Surgical Ind. Ltda, São Paulo, SP, Brazil) was inserted into the left jugular vein for drug administration. Using the Seldinger's technique, two introducer sheaths (Intro-Flex $8.5 \mathrm{Fr} ; 11 \mathrm{~cm}$, Edwards Critical Care Division, USA) were placed $10 \mathrm{~cm}$ apart in the middle third of the right jugular vein. A thermodilution catheter (7.5 Fr Swan-Ganz catheter; $130 \mathrm{~cm}$, Edwards Critical Care Division, USA) was inserted via the distal introducer sheath and a polyethylene \#240 cannula of $110 \mathrm{~cm}, 7.2 \mathrm{Fr}$ ED via the proximal introducer sheath. These were positioned in the right pulmonary artery and right atrium, respectively. Correct positioning was confirmed by observation of pressure waveforms using a multiparameter monitor (AS/3 Monitor; Datex Engström, Helsinki, Finland). ${ }^{25}$ A transverse facial artery was catheterised (Angiocath Insyte, 18G, Becton Dickinson Surgical Ind. Ltda, São Paulo, SP, Brazil) for measurement of blood pressure and blood collection for blood gas analysis. The arterial catheter was connected to a pressure transducer (TruWave Disposable Pressure Transducer; Edwards Lifesciences, São Paulo, SP, Brazil), zeroed to atmospheric pressure and levelled with the elbow joint. All the transducers were calibrated against a mercury column before each experimental session. Heart rate (HR) was recorded from the ECG electrodes (Adhesive electrodes, 2223BRO, 3M do Brasil Ltda, Sumaré, SP, Brazil) configured as a base-apex lead.

\section{Study design}

The horses were randomly allocated (by picking the prescribed treatment from a box) to receive treatment DEX or DEX/ BUT with a minimum interval of 7 days, the main investigator (LOM) being unaware of treatment. Choice of infusion rates was based on a pilot study with five horses, performed two months previously evaluating boli of $2.5,3$ and $3.5 \mu \mathrm{g} /$ $\mathrm{kg}$ and CRIs of $2,3.5,4$ and $5 \mu \mathrm{g} / \mathrm{kg} / \mathrm{hour}$ DEX and $20 \mu \mathrm{g} /$ $\mathrm{kg}$ followed by $24 \mu \mathrm{g} / \mathrm{kg} /$ hour BUT (unpublished data). The treatments were prepared and administered by an assistant investigator. In DEX, $3.5 \mu \mathrm{g} / \mathrm{kg}$ DEX (Dexdomitor, $500 \mu \mathrm{g} / \mathrm{ml}$; Orion Corporation, Espoo, Finland) was given intravenously as a bolus over 10 seconds, followed by a CRI of $5 \mu \mathrm{g} / \mathrm{kg} /$ hour and a CRI of saline (same rate as BUT) for 90 minutes. In DEX/BUT, intravenous boli of $3.5 \mu \mathrm{g} / \mathrm{kg}$ DEX and $20 \mu \mathrm{g} / \mathrm{kg}$ BUT (Torbugesic $10 \mathrm{mg} / \mathrm{ml}$; Fort Dodge Animal Health Ltda, Campinas, SP, Brazil) were administered, followed by CRIs of $3.5 \mu \mathrm{g} / \mathrm{kg} / \mathrm{hour}$ DEX and $24 \mu \mathrm{g} / \mathrm{kg} /$ hour BUT for 90 minutes. All bolus doses and CRIs were diluted with saline to 5 and $20 \mathrm{ml}$, respectively, in order to ensure blinding. Constant rate infusions were delivered by two calibrated infusion pumps (ST680, Samtronic, São Paulo, SP, Brazil).

Evaluation of the different variables always followed the same order and, in order not to interfere with evaluation of sedation, HHAG (base of lip to ground measured in $\mathrm{cm}$ ), ataxia and response to stimuli were assessed before cardiopulmonary measurements were made. HHAG is a standardised, objective and quantitative measure of the degree of sedation that does not require stimulation for measurement. ${ }^{2}$ In our study, baseline HHAG was taken as 100 per cent to which all the further measurements were compared. ${ }^{1724}$ Sedation was considered 'sufficient' when the head position was $\leq 50$ per cent of the awake state. ${ }^{17}$ In addition, quality of sedation was evaluated by scoring the degree of ataxia and response to external stimuli.

\section{Evaluation of sedative effects}

After a period of 20-30 minutes of familiarisation, the HHAG was determined by the primary investigator using a measuring tape attached to the stocks. In order to evaluate the remaining sedation parameters, the whole period was videotaped and the images screened later by two experienced, independent observers, blinded to the treatment. Thus, ataxia was scored by pushing on the hind quarters to detect any swaying. The responses to tactile stimuli were tested by touching both ears simultaneously with fingers. Finally, the responses to auditory stimuli were evaluated by observing the reaction to a hand clap behind the horse. Ataxia and responses to tactile and auditory stimulation were rated from 0 (no response) to 3 (maximal response). The results for ataxia and each response to stimulus are presented as the sum of scores of the six individuals (ranging from 0 to 18), adapted from Bryant and others. ${ }^{26}$ The HHAG and the degree of ataxia were measured at all time points, at baseline (five minutes before boli injection), during infusion (at 5, 15, 30, 60 and 90 minutes) and 15, 30 and 60 minutes after the infusion was stopped (recovery). The tactile and auditory stimuli were not applied at 5 and 15 minues after treatment administration or at 15 minutes after the end of the infusions to avoid interference with evaluation of sedation.

\section{Assessment of cardiopulmonary variables}

First, HR, systolic (SAP), diastolic (DAP), mean (MAP) arterial, right atrial (RAP) and mean pulmonary arterial (MPAP) pressures, respiratory rate $\left(f_{\mathrm{R}}\right)$ and body temperature $(\mathrm{T})$ (from the thermistor of the Swan-Ganz catheter) were recorded and arterial blood samples were taken at all time points. Blood was analysed immediately after withdrawal using a blood gas analyser (Model 348 pH/Blood Gas Analyzer; Chiron Diagnostics, Halstead, UK) to measure $\mathrm{pH}$, arterial partial pressures of oxygen $\left(\mathrm{PaO}_{2}\right)$ and carbon dioxide $\left(\mathrm{PaCO}_{2}\right)$ and calculated haemoglobin saturation $\left(\mathrm{SaO}_{2}\right)$ and bicarbonate $\left(\mathrm{HCO}_{3}^{-}\right)$values.

In order to detect cardiac arrhythmias, the ECG records were printed for one minute at baseline and at 1, 5, 15, 30, 60 and 90 minutes after drug administration and 15, 30 and 60 minutes after the infusion was stopped. The percentage of second-degree atrioventricular blocks (AVB) occurring in that minute was calculated according to the equation: (number of $P$ waves not followed by ORS-T complexes)/(total number of $\mathrm{P}$ waves recorded) $\times 100$.

Finally, the cardiac output (CO) was measured using thermodilution (AS/3 Anaesthesia Monitor, Datex Engström, Helsinki, Finland). Thirty-seven $\mathrm{ml}$ (allowing for $2 \mathrm{ml}$ dead space) of cold 5 per cent glucose $\left(0^{\circ} \mathrm{C}-4^{\circ} \mathrm{C}\right)$ were injected into the right atrium over five seconds. ${ }^{25}$ Five estimations of the $\mathrm{CO}$ were made at each time point, and the mean of these values was used as the $\mathrm{CO}$. We used five $\mathrm{CO}$ measurements without selecting measurements within 10 per cent from each other. Cardiac index (CI), stroke index (SI), systemic vascular resistance index (SVRI), arterial oxygen content $\left(\mathrm{CaO}_{2}\right)$ and oxygen delivery index $\left(\mathrm{DO}_{2} \mathrm{I}\right)$ were calculated using standard equations (see online supplementary appendix 1). Respiratory rate was obtained by observation of chest movement over one minute.

\section{Statistical analysis}

Statistical analysis was performed using SAS for Windows V.9.1.3 (SAS Institute Inc. Cary, NC, USA). Normality was assessed for 


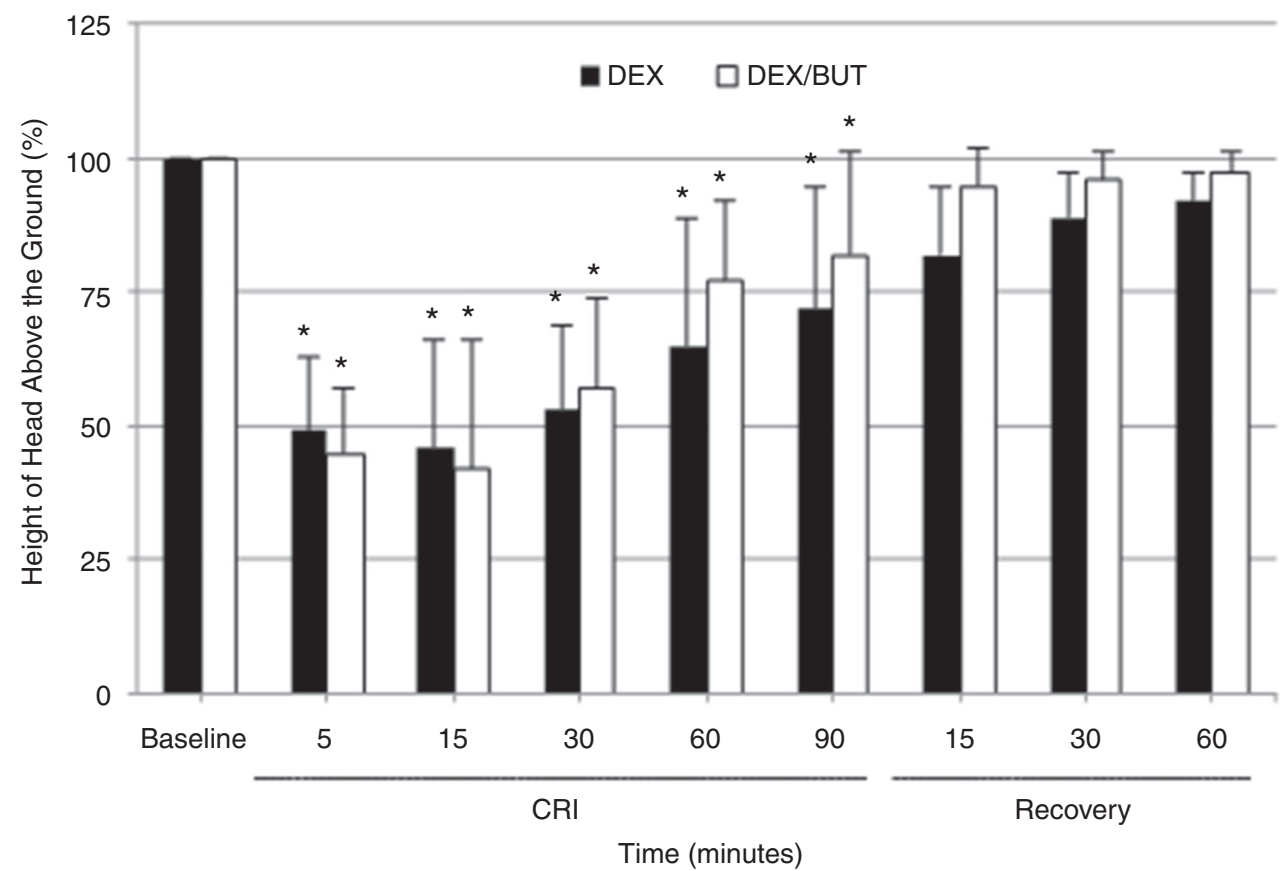

FIG 1: Height of head above the ground (per cent) evaluated before (baseline), during treatments DEX (dexmedetomidine, bolus $3.5 \mu \mathrm{g} /$ $\mathrm{kg}$ and continuous rate infusion (CRI) $5 \mu \mathrm{g} / \mathrm{kg} / \mathrm{hour}$ ) and DEX/BUT (dexmedetomidine, bolus $3.5 \mu \mathrm{g} / \mathrm{kg}, \mathrm{CRI} 3.5 \mu \mathrm{g} / \mathrm{kg} / \mathrm{hour}$ and butorphanol, bolus $20 \mu \mathrm{g} / \mathrm{kg}$ and CRI $24 \mu \mathrm{g} / \mathrm{kg} / \mathrm{hour}$ ) and after infusions for 60 minutes (recovery) in six conscious horses. * Significant differences compared with baseline. No significant differences between treatments were observed (two-way analysis of variance followed by TukeyKramer test, $\mathrm{P}<0.05)$.

all the variables by Shapiro-Wilk test and graphical analysis. Cardiopulmonary and HHAG reduction (per cent) data were evaluated by using analysis of variance for repeated measures, followed by Tukey-Kramer test. The degree of ataxia and responses to tactile and auditory stimuli, which were evaluated by the two independent observers, were analysed using Friedman's test and Dunn's test for multiple comparisons. In order to determine agreement between the results from the two observers, Wilcoxon rank-sum statistical test and the Cronbach's alpha were applied. The presence of AVBs was analysed using Wilcoxon rank-sum statistical matched paired test. Significance levels were set at 5 per cent.

\section{Results}

Each of the six horses received randomly both DEX and DEX/BUT treatments, completing the experiment without complications. At the end of the day of each session, all the horses resumed eating and defecated normally.

\section{Sedative effects}

At fiveminutes, mean HHAG values were reduced 51 and 55 per cent from baseline in DEX and DEX/BUT, respectively, while maximum reduction occurred at 15 minutes, 54 per cent and 58 per cent, respectively. Afterwards, HHAG consistently increased but remained significantly lower than baseline for 90 minutes in both treatments (Fig 1). No significant differences were detected between treatments for HHAG.

No significant difference was observed between the two observers in assessing ataxia and response to stimuli. The Cronbach's alpha values for ataxia and the responses to tactile and auditory stimuli were greater than 0.8 , indicating a high degree of concordance. Therefore, only data from the most experienced evaluator were analysed. Compared with baseline, the maximum degree of ataxia was observed five minutes after starting the infusion and persisted for up to 15 minutes in both treatments (Fig 2). Decreased responses were recorded only after the first tactile stimuli, 30 minutes after the start of both infusions. Decreased responses to auditory stimuli were seen at 30 minutes in both treatments and at 60 minutes in DEX (Fig 3). No significant differences were observed between treatments for the degree of ataxia and responses to stimuli.

\section{Cardiopulmonary variables}

Compared with baseline, HR decreased for 90 and 30 minutes, respectively after the start of DEX $(\mathrm{P}=0.036)$ and $\mathrm{DEX} / \mathrm{BUT}$ $(\mathrm{P}<0.001)$ (Table 1). Systolic arterial pressure was lower than baseline in both treatments at 15 minutes $(\mathrm{DEX}(\mathrm{P}=0.048)$; $\mathrm{DEX} / \mathrm{BUT}$ $(\mathrm{P}=0.019))$ and 30 minutes $(\mathrm{DEX}(\mathrm{P}=0.013) ; \mathrm{DEX} / \mathrm{BUT}(\mathrm{P}=0.005))$, whereas a decrease in MAP was detected only with DEX/BUT at 30 minutes $(\mathrm{P}=0.007)$ (Table 1$)$. In both treatments, CI (DEX $(\mathrm{P}=0.025) ; \mathrm{DEX} / \mathrm{BUT}(\mathrm{P}<0.001))$ and $\mathrm{DO}_{2} \mathrm{I}$ decreased during the first 30 minutes (DEX $(\mathrm{P}<0.001)$; DEX/BUT $(\mathrm{P}<0.001)$ ) (Table 1; Table 2). In both treatments, SVRI increased for the first 15 minutes (DEX $(\mathrm{P}=0.025)$; DEX/BUT $(\mathrm{P}<0.001))$. For MPAP, significant decreases were observed for DEX at 60 minutes after the bolus administration $(\mathrm{P}=0.0443)$, and at 15 minutes in treatment $\mathrm{DEX} /$ $\mathrm{BUT}(\mathrm{P}=0.0229)$. No changes from baseline were observed during the whole observation period for DAP, SI and RAP. No significant differences between treatments were detected for any cardiopulmonary variables (Table 1 ; Table 2 )

All horses in the DEX treatment developed AVBs (30 (17 - 45)) (median (lower - upper limit)) per cent, whereas this occurred in only three horses after the DEX/BUT bolus (47 $(29$ - 53)) per cent, at one minute after drug administration. At five minutes, AVBs were observed in three and five horses in treatments DEX (24 (22-29)) per cent and DEX/BUT (17 (6 -38)) per cent, respectively. At 15 minutes, only three horses in DEX (6 (6-12)) per cent and one horse (13 per cent) in DEX/ BUT exhibited AVBs. Only after this time point, the horse in DEX/BUT had a 19 and 7 per cent incidence of AVBs at 30 and 60 minutes, respectively.

Respiratory rate decreased significantly below baseline during the infusion in both treatments, and for 30 minutes in the recovery period in DEX only (Table 2). No changes from baseline nor differences between treatments were observed for $\mathrm{PaO}_{2}$ and $\mathrm{PaCO}_{2}$ (Table 2). 


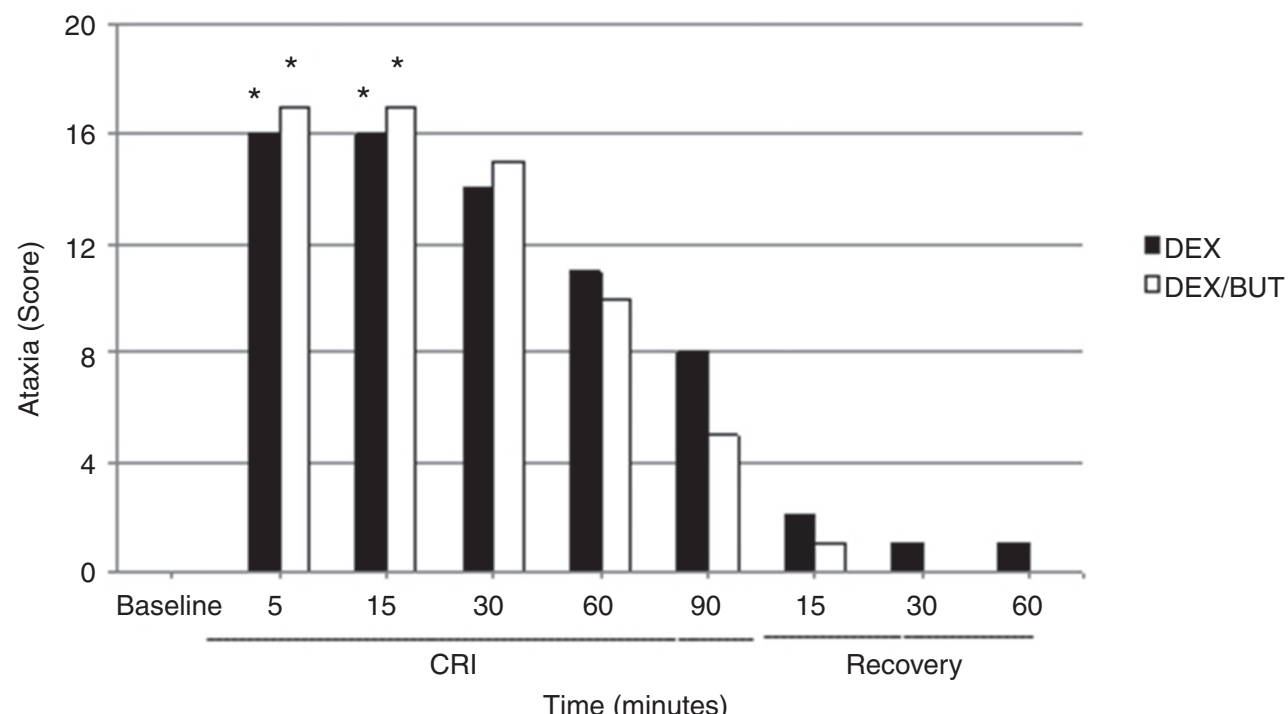

FIG 2: Ataxia (score) evaluated before (baseline), during treatments DEX (dexmedetomidine, bolus $3.5 \mu \mathrm{g} / \mathrm{kg}$ and continuous rate infusion (CRI) $5 \mu \mathrm{g} / \mathrm{kg} / \mathrm{hour}$ ) and DEX/BUT (dexmedetomidine, bolus $3.5 \mu \mathrm{g} / \mathrm{kg}$, CRI $3.5 \mu \mathrm{g} / \mathrm{kg} / \mathrm{hour}$ and butorphanol, bolus $20 \mu \mathrm{g} / \mathrm{kg}$ and CRI $24 \mu \mathrm{g} /$ $\mathrm{kg} / \mathrm{hour}$ ) and after infusions for 60 minutes (recovery) in six conscious horses. Higher scores mean higher degrees of ataxia. ${ }^{*}$ Significant differences compared with baseline. No significant differences between treatments were observed (Friedman's test with Dunn's multiple comparisons, $\mathrm{P}<0.05)$.

\section{Discussion}

Based on HHAG, DEX and DEX/BUT provided clinically sufficient sedation for 30 minutes, and were associated with similar sedative and cardiopulmonary effects.

A $3.5 \mu \mathrm{g} / \mathrm{kg}$ DEX bolus was used as previously reported in horses..$^{11415}$ Horses in the combination treatment additionally received a bolus of BUT, aiming to potentiate the sedative properties of DEX and to provide extra analgesia. A bolus of $20 \mu \mathrm{g} / \mathrm{kg}$ was chosen because this dose has minimum effects on cardiopulmonary function, when given alone, ${ }^{27}$ or combined with other $\alpha_{2}$-agonists. ${ }^{28}$

The infusion rates of DEX were based on a pilot study (unpublished data). Although $1.75 \mu \mathrm{g} / \mathrm{kg} /$ hour DEX was expected to be equivalent to $3.5 \mu \mathrm{g} / \mathrm{kg} /$ hour of medetomidine, ${ }^{91415}$ that rate did not provide an adequate level of sedation. Therefore, the infusion rate was increased to $5 \mu \mathrm{g} / \mathrm{kg} / \mathrm{hour}$ in DEX, whereas horses in DEX/BUT received a DEX CRI of $3.5 \mu \mathrm{g} / \mathrm{kg} /$ hour and BUT at $24 \mu \mathrm{g} / \mathrm{kg} /$ hour. ${ }^{2224}$ Adding a BUT infusion would enable a reduced DEX rate to maintain a similar degree of sedation, while reducing the DEX-related side effects. Moreover, DEX rates ranging from 4 to $6 \mu \mathrm{g} / \mathrm{kg} /$ hour provide analgesia in horses. ${ }^{17}$

Reduction of HHAG of more than 50 per cent of baseline values occurred in both treatments for 15 minutes. The HHAG is used as a measure of the degree of sedation after $\alpha_{2}$-agonist administration, where a head position equal to or lower than 50 per cent of the awake state is considered as 'sufficient' sedation. ${ }^{17}$ Although HHAG reduction at 30 minutes was close to, but less than 50 per cent in both treatments, the horses were still sedated to a degree which may be useful under clinical conditions. In this case, the opioid-linked behavioural effects might have overcome the sedation produced by the $\alpha_{2}$-agonist, especially as low doses of the $\alpha_{2}$-agonist were used. ${ }^{29}$ However, after this time point, HHAG gradually increased until the end of the infusion, not reaching 'sufficient' sedation. In contrast, studies with romifidine and xylazine produced HHAG values below 50 per cent for the whole 120 minutes infusion. ${ }^{2} \mathrm{~A}$ constant sedation with a medetomidine CRI was reported by Bettschart-Wolfensberger and others, ${ }^{8}$ who used that drug at lower doses than the considered equipotent dosage of DEX used in our study. This difference could be a consequence of measuring only the cardiopulmonary parameters in their study and the horses were not stimulated. Minor movements of head or ears were noted after minimal stimuli such as blood collection. ${ }^{8}$
The absence of a steady sedation state could be explained by the DEX's pharmacokinetics, which include a rapid clearance of the drug resulting in a short half-life. ${ }^{11}{ }^{12}$ When given as a bolus before general anaesthesia at the clinically reported doses ( $3.5 \mu \mathrm{g} /$ $\mathrm{kg}$ ), DEX was not as good a sedative as other $\alpha_{2}$-agonists in horses: Marcilla and others ${ }^{15}$ and Marly-Voquer and other ${ }^{13}$ reported that redosage was required to obtain good sedation. When given as a CRI, DEX produces its effects, including sedation, immediately without any delay. Moreover, individual differences were reported between the plasma concentration and its pharmacodynamic effects which make the calculations uncertain ${ }^{12}$; as a result, the authors recommend individual adjustments to effect rather than infusing at a predetermined value.

The degree of ataxia and responses to tactile and auditory stimuli scores were considered acceptable in the present study. These effects were of shorter duration than after other $\alpha_{2}$-agonists alone or in combination with opioids, including detomidine, ${ }^{6}$ xylazine and romifidine. ${ }^{2}$

Typical cardiopulmonary side effects of $\alpha_{2}$-agonists were observed in both treatments, always within clinically acceptable limits. The most relevant included the reduction in $\mathrm{HR}, \mathrm{CI}, \mathrm{DO}_{2} \mathrm{I}$ and MPAP, mainly occurring after bolus administration in both treatments as seen in studies with ponies ${ }^{11}$ and with other $\alpha_{2}$-agonists. ${ }^{38}$ Values of SAP and MAP did not show the typical high values after DEX bolus administration, ${ }^{11}$ but showed occasional lower values between 15 and 30 minutes.

When a CRI was added, CI decreased in a similar way to that seen after a medetomidine CRI, ${ }^{8}$ even when the doses here were higher than those considered equipotent. Whereas CI after a medetomidine $5 \mu \mathrm{g} / \mathrm{kg}$ bolus followed by a CRI of $3.5 \mu \mathrm{g} / \mathrm{kg} /$ hour returned to baseline at 40 minutes, in our study this took 60 minutes. However, we did not take measurements between 30 and 60 minutes, which would have allowed further comparison of the drugs' effects. Infusions of other $\alpha_{2}$-agonists such as xylazine and romifidine decreased CI for up to two hours. ${ }^{3}$ Detomidine infusions have the greatest impact on CI, reducing it to 50 per cent below baseline. ${ }^{5}$ This reduction in CI was attributable to the observed decreases in HR, as SI remained constant during the whole period, as seen with other $\alpha_{2}$-agonists. ${ }^{3}$ The associated decreases in $\mathrm{DO}_{2} \mathrm{I}$ over the same time period are of clinical significance, and may be particularly serious in compromised horses. However, these changes in CI and related parameters between studies should be interpreted carefully, mainly because 
A

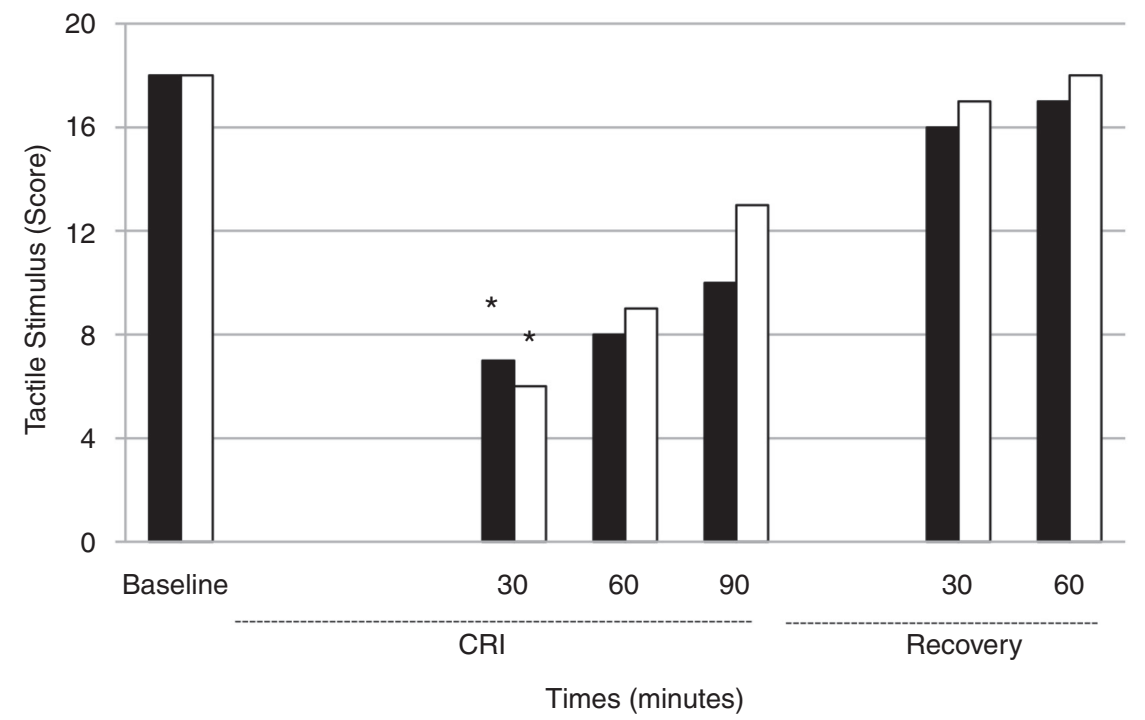

aEX 口DEX/BUT

B

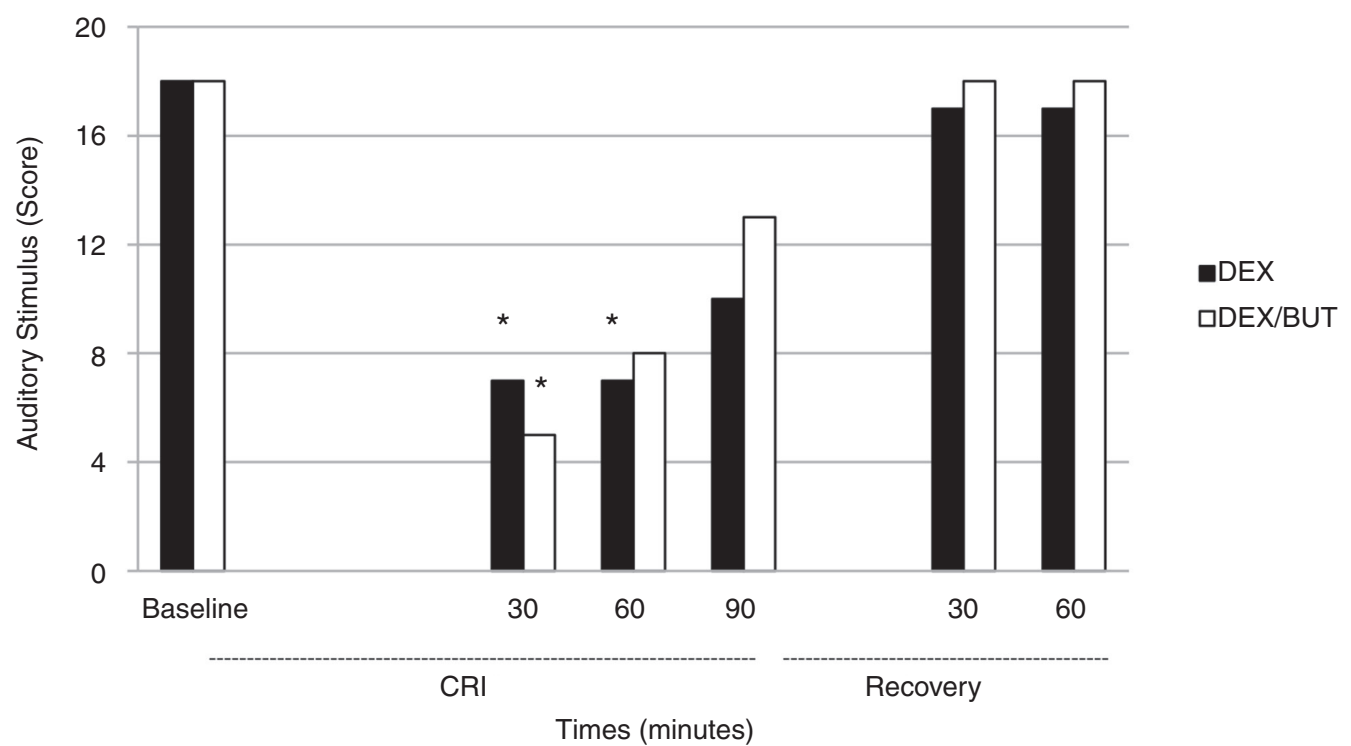

FIG 3: (A-B) Tactile and auditory stimuli (scores) evaluated before (baseline), during treatments DEX (dexmedetomidine, bolus $3.5 \mu \mathrm{g} /$ $\mathrm{kg}$ and continuous rate infusion (CRI) $5 \mu \mathrm{g} / \mathrm{kg} / \mathrm{hour}$ ) and DEX/BUT (dexmedetomidine, bolus $3.5 \mu \mathrm{g} / \mathrm{kg}, \mathrm{CRI} 3.5 \mu \mathrm{g} / \mathrm{kg} / \mathrm{hour}$ and butorphanol, bolus $20 \mu \mathrm{g} / \mathrm{kg}$ and CRI $24 \mu \mathrm{g} / \mathrm{kg} / \mathrm{hour}$ ) and after infusions for 60 minutes (recovery) in six conscious horses. Stimuli were not performed at 5 and 15 minutes during $\mathrm{CRI}$ and at 15 minutes of the recovery, in order to avoid interferences with haemodynamic values. Higher scores indicate lower sedation. *Significant differences compared with baseline. No significant differences between treatments were observed (Friedman's test with Dunn's multiple comparisons, $\mathrm{P}<0.05$ ).

the sedation degrees were different, and the doses not always equipotent.

The initial increases in SVRI observed in both treatments were short-lived and can be explained by the peripherally mediated vasoconstriction after bolus administration of $\alpha_{2}$-agonists in horses. ${ }^{30-32}$ These increases in SVRI did not correlate with increases in MAP, an effect which was seen with boli of medetomidine, ${ }^{9}$ xylazine and romifidine. ${ }^{3}$ This discrepancy is probably due to differences in the duration of action and to selectivity for $\alpha_{2}$ versus $\alpha_{1}$ adrenoreceptors. The influence of diuresis may also be important, as minimal decreases in MAP may be induced by slight reduction in circulating volume, ${ }^{3}$ especially in long procedures. Unfortunately, urine output was not measured, although it is well known that $\alpha_{2}$-agonists increase urine production. ${ }^{334}$

Minimal decreases in MPAP were observed at the beginning of the infusion. This is in contrast to the earlier study of Bettschart-Wolfensberger and others, ${ }^{11}$ where an increase in MPAP was reported after a DEX bolus. The MPAP was increased with romifidine ${ }^{332}$ but not xylazine ${ }^{3}$ and variable results have been reported after detomidine administration. ${ }^{53}$ This may be important under clinical conditions as pulmonary hypertension occurring with swelling of nasal mucous membranes and increased mechanical effort may be detrimental. In these circumstances, the $\alpha_{2}$-agonist with the least effect on MPAP would appear to be the best choice.

The persistence of AVBs for 15 minutes was a result of bolus administration. Similar results were observed in ponies after intravenous medetomidine $7 \mu \mathrm{g} / \mathrm{kg}$, where cardiac arrhythmias appeared immediately, but normal rhythm returned after seven minutes. ${ }^{9}$ BUT administration was unlikely to influence the incidence of arrhythmias as it was not reported to be arrhythmogenic in previous studies. ${ }^{18}$

As expected, $f_{R}$ was reduced with both treatments, most probably associated with the DEX, as seen with other $\alpha_{2}$-agonists. ${ }^{31}$ The co-administration of BUT was considered to have no significant effect on $f_{R}$, and this finding is consistent with previous reports describing BUT in horses. ${ }^{22} 27$ The decrease in $f_{R}$ did not lead to hypoventilation, as $\mathrm{PaCO}_{2}$ remained constant, 
TABLE 1: Mean \pm SD of heart rate (HR), systolic, mean and diastolic blood pressures (SAP, MAP and DAP), cardiac index (CI), stroke index (SI), systemic vascular resistance index (SVRI), right atrial pressure (RAP) and mean pulmonary arterial pressure (MPAP) before (baseline), during continuous rate infusion (CRI) of dexmedetomidine (bolus $3.5 \mu \mathrm{g} / \mathrm{kg}$ and CRI $5 \mu \mathrm{g} / \mathrm{kg} / \mathrm{hour}$ ) in treatment DEX and dexmedetomidine (bolus $3.5 \mu \mathrm{g} / \mathrm{kg}$ and CRI $3.5 \mu \mathrm{g} / \mathrm{kg} / \mathrm{hour}$ ) and butorphanol (bolus $20 \mu \mathrm{g} / \mathrm{kg}$ and CRI $24 \mu \mathrm{g} / \mathrm{kg} / \mathrm{hour}$ ) in treatment DEX/BUT and after discontinuation of CRIs (recovery) in six standing horses

\begin{tabular}{|c|c|c|c|c|c|c|c|c|c|c|}
\hline & & \multicolumn{9}{|l|}{ Time (min) } \\
\hline & & \multirow[b]{2}{*}{ Baseline } & \multicolumn{5}{|l|}{ CRI } & \multicolumn{3}{|l|}{ Recovery } \\
\hline & & & 5 & 15 & 30 & 60 & 90 & 15 & 30 & 60 \\
\hline \multirow[t]{2}{*}{ HR (beats/minute) } & DEX & $44 \pm 3$ & $29 \pm 4 *$ & $32 \pm 3 *$ & $34 \pm 4$ & $36 \pm 4$ & $36 \pm 4$ & $41 \pm 7$ & $41 \pm 5$ & $41 \pm 6$ \\
\hline & DEX/BUT & $43 \pm 5$ & $30 \pm 4$ & $32 \pm 4$ & $33 \pm 2 *$ & $36 \pm 2$ & $38 \pm 4$ & $44 \pm 6$ & $49 \pm 8$ & $46 \pm 9$ \\
\hline \multirow[t]{2}{*}{ SAP $(\mathrm{mmHg})$} & DEX & $150 \pm 8$ & $149 \pm 8$ & $134 \pm 6$ & $129 \pm 6$ & $128 \pm 17$ & $128 \pm 17$ & $128 \pm 15$ & $134 \pm 13$ & $146 \pm 5$ \\
\hline & DEX/BUT & $152 \pm 5$ & $146 \pm 11$ & $133 \pm 9 *$ & $127 \pm 10^{*}$ & $134 \pm 22$ & $140 \pm 19$ & $149 \pm 20$ & $155 \pm 14$ & $158 \pm 10$ \\
\hline \multirow[t]{2}{*}{ MAP (mmHg) } & DEX & $115 \pm 3$ & $119 \pm 7$ & $107 \pm 7$ & $103 \pm 5$ & $101 \pm 14$ & $101 \pm 13$ & $100 \pm 9$ & $105 \pm 7$ & $113 \pm 8$ \\
\hline & DEX/BUT & $119 \pm 8$ & $118 \pm 5$ & $105 \pm 7$ & $101 \pm 9^{*}$ & $105 \pm 17$ & $111 \pm 15$ & $115 \pm 13$ & $119 \pm 12$ & $120 \pm 12$ \\
\hline \multirow[t]{2}{*}{$\mathrm{DAP}(\mathrm{mmHg})$} & DEX & $95 \pm 8$ & $103 \pm 8$ & $90 \pm 9$ & $88 \pm 8$ & $86 \pm 12$ & $85 \pm 10$ & $83 \pm 6$ & $89 \pm 3$ & $91 \pm 8$ \\
\hline & DEX/BUT & $99 \pm 9$ & $99 \pm 5$ & $89 \pm 7$ & $86 \pm 11$ & $87 \pm 15$ & $92 \pm 13$ & $92 \pm 13$ & $95 \pm 11$ & $96 \pm 14$ \\
\hline \multirow[t]{2}{*}{ Cl (ml/minute/kg) } & DEX & $60 \pm 9$ & $38 \pm 4$ & $42 \pm 4$ & $43 \pm 6$ & $50 \pm 10$ & $49 \pm 7$ & $53 \pm 8$ & $58 \pm 14$ & $64 \pm 12$ \\
\hline & DEX/BUT & $63 \pm 6$ & $37 \pm 4$ & $43 \pm 4$ & $47 \pm 5^{*}$ & $54 \pm 15$ & $52 \pm 7$ & $69 \pm 20$ & $80 \pm 16$ & $68 \pm 8$ \\
\hline \multirow[t]{2}{*}{$\mathrm{SI}(\mathrm{ml} / \mathrm{kg})$} & DEX & $1.38 \pm 0.18$ & $1.34 \pm 0.22$ & $1.34 \pm 0.12$ & $1.27 \pm 0.18$ & $1.37 \pm 0.14$ & $1.36 \pm 0.12$ & $1.29 \pm 0.25$ & $1.42 \pm 0.21$ & $1.55 \pm 0.14$ \\
\hline & DEX/BUT & $1.50 \pm 0.27$ & $1.25 \pm 0.14$ & $1.35 \pm 0.09$ & $1.42 \pm 0.10$ & $1.50 \pm 0.37$ & $1.40 \pm 0.15$ & $1.54 \pm 0.29$ & $1.63 \pm 0.21$ & $1.51 \pm 0.20$ \\
\hline \multirow{2}{*}{$\begin{array}{l}\text { SVRI (dynes/s/ } \\
\left.\mathrm{cm}^{5} / \mathrm{kg}\right)\end{array}$} & DEX & $129.0 \pm 14.7$ & $210.3 \pm 13.8^{*}$ & $170.0 \pm 25.6$ & $160.9 \pm 31.9$ & $142.3 \pm 36.8$ & $142.8 \pm 21.8$ & $129.4 \pm 18.5$ & $127.2 \pm 23.6$ & $124.6 \pm 28.0$ \\
\hline & DEX/BUT & $132.1 \pm 19.3$ & $218.0 \pm 24.6$ & $169.7 \pm 16.4$ & $147.7 \pm 18.1$ & $137.6 \pm 21.3$ & $146.8 \pm 20.3$ & $125.4 \pm 40.3$ & $109.2 \pm 29.0$ & $124.2 \pm 20.8$ \\
\hline \multirow[t]{2}{*}{ RAP (mmHg) } & DEX & $19 \pm 2$ & $20 \pm 2$ & $18 \pm 3$ & $18 \pm 2$ & $16 \pm 3$ & $15 \pm 4$ & $16 \pm 3$ & $17 \pm 2$ & $17 \pm 2$ \\
\hline & DEX/BUT & $16 \pm 2$ & $17 \pm 2$ & $14 \pm 2$ & $15 \pm 2$ & $15 \pm 2$ & $15 \pm 3$ & $15 \pm 3$ & $15 \pm 3$ & $15 \pm 2$ \\
\hline \multirow[t]{2}{*}{ MPAP $(\mathrm{mmHg})$} & DEX & $34 \pm 3$ & $33 \pm 4$ & $32 \pm 4$ & $30 \pm 4$ & $29 \pm 5$ & $29 \pm 5$ & $30 \pm 4$ & $31 \pm 5$ & $34 \pm 4$ \\
\hline & DEX/BUT & $32 \pm 2$ & $31 \pm 2$ & $29 \pm 2 *$ & $29 \pm 1$ & $30 \pm 3$ & $30 \pm 5$ & $31 \pm 2$ & $31 \pm 3$ & $32 \pm 4$ \\
\hline
\end{tabular}

"Significant differences compared with baseline $(\mathrm{P}<0.05)$.

following the same pattern as with xylazine, ${ }^{3136}$ detomidine ${ }^{3031}$ and medetomidine. ${ }^{31}$

Overall, the lack of difference between treatments may be explained by a synergistic effect of adding a CRI of BUT to the lower rate of DEX, confirming our initial hypothesis. However, this assumption has to be made with circumspection as a third treatment with BUT alone was not studied. Its inclusion may have been of value to detect the sedative and cardiopulmonary effects produced by this drug alone, or if any potentiation occurred. However, we opted not to study a BUT-only treatment as this drug alone in healthy pain-free standing horses is likely to induce undesirable behavioural effects..$^{22} 3738$

Our study has a number of limitations. First, it may be argued that the choice of doses was not ideal; a reduced dose of DEX could have been given with the BUT. Reducing the DEX loading dose below $3.5 \mu \mathrm{g} / \mathrm{kg}$ may produce inadequate sedation. ${ }^{13}{ }^{15}$ Different DEX infusion rates were used, making it difficult to compare the effects of BUT. However, we aimed to avoid the side effects of the infused DEX by reducing its rate and adding BUT. A second limitation was that steady sedation and probably steady plasma concentrations were not achieved. As cited above, this could be explained by the horses being stimulated for evaluation of sedation. However, stimulation inevitably occurs under clinical conditions, which is the very reason for evaluating sedation.

In conclusion, the hypothesis that the addition of BUT to a reduced DEX infusion would enhance the sedative qualities and duration was not proven. At the doses and rates reported here, both regimens provided clinically sufficient sedation for 30 minutes, then steadily decreasing until the end of the infusion. Future studies are justified to determine whether alternative dosages, or individual adjustments that produce rapid changes in sedation depth might produce the desired effect.

\section{Acknowledgements}

The authors would like to thank the Fundação de Amparo à Pesquisa do Estado de São Paulo (FAPESP) for the funding support (Scholarship grantnumbers 2008/54415-9 and 2007/57833-3) and to Dr Denise F Rodrigues for her invaluable assistance.

Competing interests None declared.

(c) British Veterinary Association (unless otherwise stated in the text of the article) 2017. All rights reserved. No commercial use is permitted unless otherwise expressly granted.

- Additional material is published online only. To view please visit the journal online (http://dx.doi.org/10.1136/vr.104359).

\section{References}

1 RINGER SK, PORTIER KG, FOUREL I, et al. Development of a xylazine constant rate infusion with or without butorphanol for standing sedation of horses. Vet Anaesth Analg 2012;39:1-11.

2 RINGER SK, PORTIER K, TORGERSON PR, et al. The effects of a loading dose followed by constant rate infusion of xylazine compared with romifidine on sedation, ataxia and response to stimuli in horses. Vet Anaesth Analg 2013:40:157-65.

3 RINGER SK, SCHWARZWALD CC, PORTIER KG, et al. Effects on cardiopulmonary function and oxygen delivery of doses of romifidine and xylazine followed by constant rate infusions in standing horses. Vet J 2013;195:228-34.

4 WILSON DV, BOHART GV, EVANS AT, et al. Retrospective analysis of detomidine infusion for standing chemical restraint in 51 horses. Vet Anaesth Analg 2002;29:54-7.

5 AGUIAR AJA, MEDEIROS LQ, DESSEN MR, et al. Hemodynamic and sedative effects of constant rate infusions of detomidine associated with Butorphanol, and detomidine alone in conscious horses. Vet Anaesth Analg 2010;37:20.

6 TAYLOR P, COUMBE K, HENSON F, et al. Evaluation of sedation for standing clinical procedures in horses using detomidine combined with buprenorphine. Vet Anaesth Analg 2014:41:14-24.

7 RINGER SK, PORTIER KG, FOUREL I, et al. Development of a romifidine constant rate infusion with or without butorphanol for standing sedation of horses. Vet Anaesth Analg 2012;39:12-20.

8 BETTSCHART-WOLFENSBERGER R, BETTSCHART RW, VAINIO O, et al. Cardiopulmonary effects of a two hour infusion of medetomidine and its reversal by atipamezole in horses and ponies. J Vet Anaesth 1999;26:8-12.

9 BETTSCHART-WOLFENSBERGER R, CLARKE KW, VAINIO O, et al Pharmacokinetics of medetomidine in ponies and elaboration of a medetomidine infusion regime which provides a constant level of sedation. Res Vet $S_{c i}$ 1999;67:41-6.

10 SOLANO AM, VALVERDE A, DESROCHERS A, et al. Behavioural and cardiorespiratory effects of a constant rate infusion of medetomidine and morphine for sedation during standing laparoscopy in horses. Equine Vet $J$ 2009;41:153-9. 


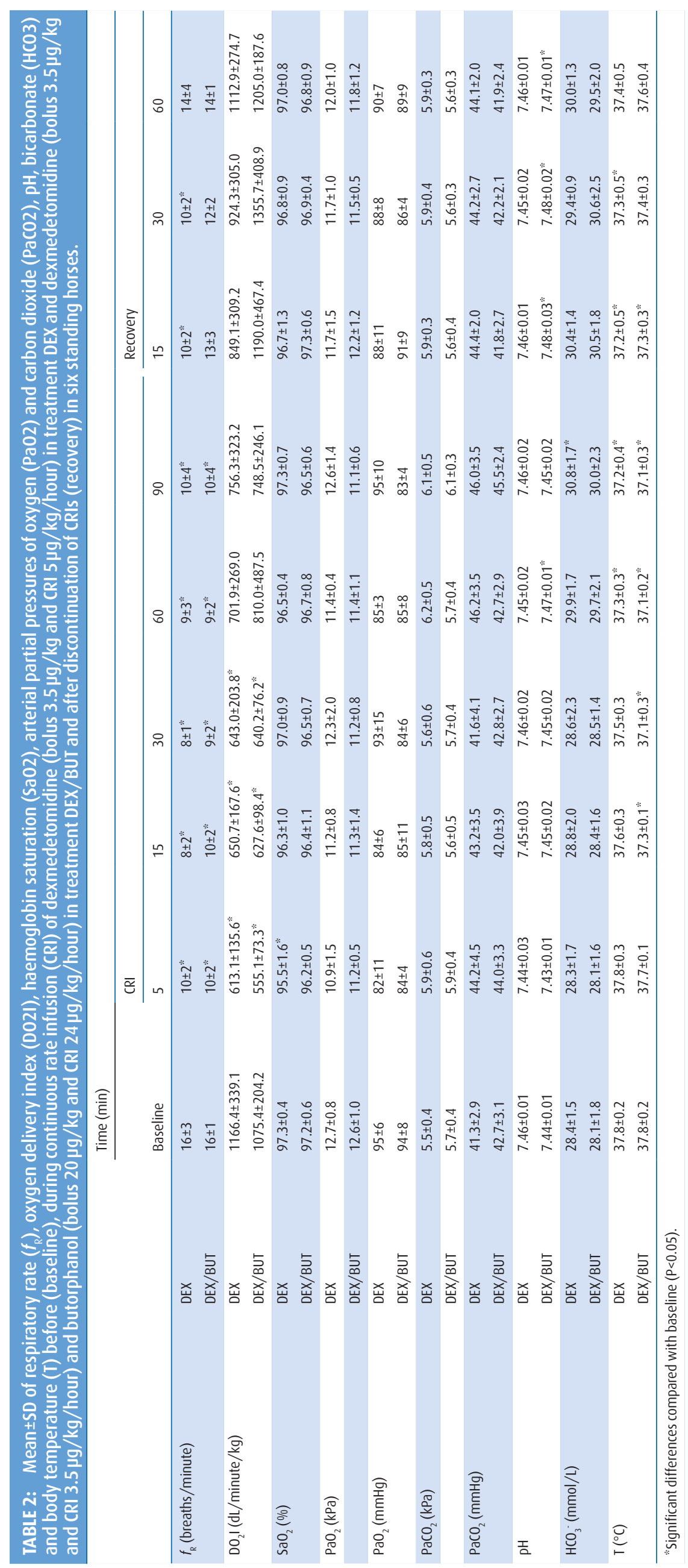

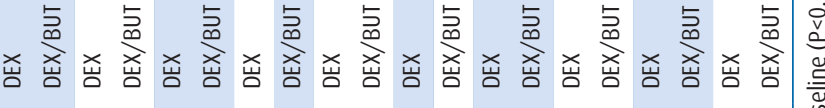


11 BETTSCHART-WOLFENSBERGER R, FREEMAN SL, BOWEN IM, et al. Cardiopulmonary effects and pharmacokinetics of i.v. dexmedetomidine in ponies. Equine Vet J 2005;37:60-4

12 RANHEIM B, RISBERG AI, SPADAVECCHIA C, et al. The pharmacokinetics of dexmedetomidine administered as a constant rate infusion in horses. $J$ Vet Pharmacol Ther 2015;38:93-6.

13 MARLY-VOQUER C, SCHWARZWALD CC, BETTSCHART WOLFENSBERGER $R$. The use of dexmedetomidine continuous rate infusion for horses undergoing transvenous electrical cardioversion-A case series. Can Vet J 2016;57:70-5

14 MARCILLA MG, SCHAUVLIEGE S, DUCHATEAU L, et al. Cardiopulmonary effects of two constant rate infusions of dexmedetomidine in isoflurane anaesthetized ponies. Vet Anaesth Analg 2010;37:311-21.

15 MARCILLA MG, SCHAUVLIEGE S, SEGAERT S, et al. Influence of a constant rate infusion of dexmedetomidine on cardiopulmonary function and recovery quality in isoflurane anaesthetized horses. Vet Anaesth Analg 2012;39:49-58.

16 RISBERG ÅI, RANHEIM B, KRONTVEIT RI, et al. The cardiovascular status of isoflurane-anaesthetized horses with and without dexmedetomidine constant rate infusion evaluated at equivalent depths of anaesthesia. Vet Anaesth Analg 2016;43:412-23

17 RISBERG A, SPADAVECCHIA C, RANHEIM B, et al. Antinociceptive effects of three escalating dexmedetomidine and lignocaine constant rate infusions in conscious horses. Vet J 2014;202:489-97.

18 CLARKE KW, PATON BS. Combined use of detomidine with opiates in the horse. Equine Vet J 1988;20:331-4

19 TAYLOR PM, BROWNING AP, HARRIS CP. Detomidine-butorphanol sedation in equine clinical practice. Vet Rec 1988;123:388-90

20 BROWNING AP, COLLINS JA. Sedation of horses with romifidine and butorphanol. Vet Rec 1994;134:90-1.

21 SCHATZMAN U, ARMBRUSTER S, STUCKI F, et al. Analgesic effect of butorphanol and levomethadone in detomidine sedated horses. Journal of veterinary medicine. A, Physiology, Pathology. Clin Med 2001;48:337-42.

22 SELLON DC, MONROE VL, ROBERTS MC, et al. Pharmacokinetics and adverse effects of butorphanol administered by single intravenous injection or continuous intravenous infusion in horses. Am J Vet Res 2001;62:183-9.

23 BENREDOUANE K, RINGER SK, FOUREL I, et al. Comparison of xylazine-butorphanol and xylazine-morphine-ketamine infusions in horses undergoing a standing surgery. Vet Rec 2011;169:364.

24 MARLY C, BETTSCHART-WOLFENSBERGER R, NUSSBAUMER P, et al Evaluation of a romifidine constant rate infusion protocol with or without butorphanol for dentistry and ophthalmologic procedures in standing horses. Vet Anaesth Analg 2014;41:491-7.
25 MUIR WW, SKARDA RT, MILNE DW. Estimation of cardiac output in the horse by thermodilution techniques. Am J Vet Res 1976;37:697-700.

26 BRYANT CE, ENGLAND GC, CLARKE KW. Comparison of the sedative effects of medetomidine and xylazine in horses. Vet Rec 1991;129:421-3.

27 ROBERTSON JT, MUIR WW, SAMS R. Cardiopulmonary effects of butorphanol tartrate in horses. Am J Vet Res 1981;42:41-4

28 CLARKE KW, ENGLAND GCW, GOOSSENS L. Sedative and cardiovascular effects of romifidine, alone and in combination with butorphanol, in the horse. J Vet Anaesth 1991;18:25-9.

29 GOZALO-MARCILLA M, LUNA SPL, CROSIGNANI N, et al. Sedative and antinociceptive effects of detomidine, methadone and different combinations in standing horses. Vet Anaesth Analg 2016.

30 WAGNER AE, MUIR WW, HINCHCLIFF KW. Cardiovascular effects of xylazine and detomidine in horses. Am J Vet Res 1991;52:651-7.

31 YAMASHITA K, TSUBAKISHITA S, FUTAOK S, et al. Cardiovascular effects of Medetomidine, detomidine and xylazine in horses. J Vet Med Sci 2000;62:1025-32.

32 FREEMAN SL, BOWEN IM, BETTSCHART-WOLFENSBERGER $\mathrm{R}$, et al. Cardiovascular effects of romifidine in the standing horse. Res Vet $\mathrm{Sci}$ 2002;72:123-9.

33 THURMON JC, STEFFEY EP, ZINKL JG, et al. Xylazine causes transient dose-related hyperglycemia and increased urine volumes in mares. Am J Vet Res 1984:45:224-7.

34 GASTHUYS F, TERPSTRA P, VAN DEN HENDE C, et al. Hyperglycaemia and diuresis during sedation with detomidine in the horse. Zentralbl Veterinarmed $A$ 1987;34:641-8.

35 NYMAN G, MARNTELL S, EDNER A, et al. Effect of sedation with detomidine and butorphanol on pulmonary gas exchange in the horse. Acta Vet Scand 2009:51:22

36 KERR DD, JONES EW, HUGGINS K, et al. Sedative and other effects of xylazine given intravenously to horses. Am J Vet Res 1972;33:525-32.

37 NOLAN AM, BESLEY W, REID J, et al. The effects of butorphanol on locomotor activity in ponies: a preliminary study. J Vet Pharmacol Ther 1994;17:323-6.

38 SELLON DC, ROBERTS MC, BLIKSLAGER AT, et al. Effects of continuous rate intravenous infusion of butorphanol on physiologic and outcome variables in horses after celiotomy. J Vet Intern Med 2004;18:555-63.

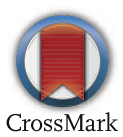

